\title{
STUDIES OF THE Cu-Mn SYSTEM
}

\author{
E.-M. Nicht, G. Brauer \\ Positron Group of TU Dresden at Research Centre Rossendorf Inc. \\ P.O.Box 510119, 01314 Dresden, Germany \\ Zs. KaJcsos and B. MolnaR \\ Central Research Institute for Physics, Hungarian Academy of Sciences \\ P.O.Box 49, 1525 Budapest, Hungary
}

\begin{abstract}
The superstructures $\mathrm{Cu}_{3} \mathrm{Mn}$ and $\mathrm{Cu}_{5} \mathrm{Mn}$ have been characterized for the first time by $\mathrm{X}$-ray and differential scanning calorimetry measurements. In addition, positron lifetime measurements are presented in order to show the defect structure of these alloys. It turned out that the annealing behaviour is equal for the two different alloys and the two different deforming processes. An annealing temperature of $300^{\circ} \mathrm{C}$ is not sufficient to obtain a defect free state.
\end{abstract}

PACS numbers: $78.70 . \mathrm{Bj}$

\section{Introduction}

The changes in mechanical properties of reactor pressure vessel (RPV) steels during their irradiation in a nuclear power plant are known as neutron embrittlement. The observed changes are thought to be correlated with the formation of precipitates. In RPV steels type 15kh2MFA and 15kh2NMFA, respectively, carbides are assumed to be such precipitates [1], whereas in RPV steels type A533B the formation of CuMn precipitates is suggested. Based on calculations, given in Refs. [2,3], the precipitates are thought to be $\mathrm{Cu}_{3} \mathrm{Mn}$ and $\mathrm{Cu}_{5} \mathrm{Mn}$, respectively.

Several investigations have already been done to enlighten the properties of the system $\mathrm{Cu}-\mathrm{Mn}$ [4-6]. In the $\mathrm{Cu}-\mathrm{Mn}$ phase diagram the existence of two regions with well-developed short-range orders is assumed [7] (Fig. 1). These $\mathrm{Cu}-\gamma-\mathrm{Mn}$ short-range-order regions are interpreted as the superstructures $\mathrm{Cu}_{3} \mathrm{Mn}$ and $\mathrm{Cu}_{5} \mathrm{Mn}$, respectively.

The goal of our studies is to enlighten the properties of $\mathrm{Cu}_{3} \mathrm{Mn}$ and $\mathrm{Cu}_{5} \mathrm{Mn}$ and to solve questions concerning defect structure, ordering effects and thermal stability of these alloys. By means of X-ray investigations the lattice parameters are to be determined. Differential scanning calorimetry (DSC) measurements are used to show ordering effects. Finally, the defect structure and annealing behaviour of these alloys are firstly enlightened by positron lifetime measurements and first results shall be presented. 


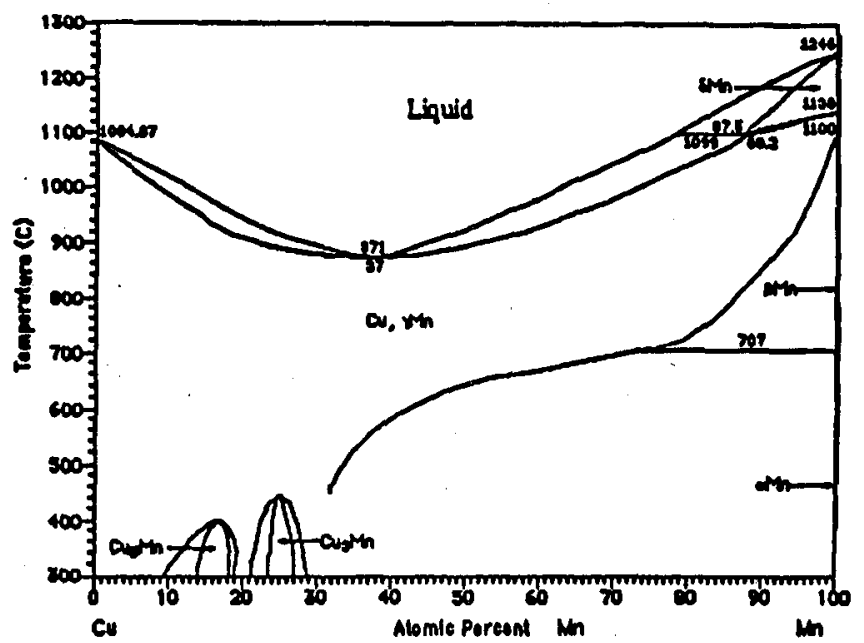

Fig. 1. $\mathrm{Cu}-\mathrm{Mn}$ phase diagram.

\section{Experimental}

To study the above-mentioned system, ingots of $\mathrm{Cu}-16 \mathrm{at} \% \mathrm{Mn}$ and $\mathrm{Cu}-25 \mathrm{at} \% \mathrm{Mn}$ were alloyed. These ingots were deformed by hammering and rolling, respectively. The different ways of deformation were chosen to investigate whether different deformation processes cause different defects and therefore different results of the lifetime measurements. The samples were prepared by separating of $1 \mathrm{~mm}$ thick discs from the hammered rods and by manufacturing of $8 \times 8 \mathrm{~mm}$ pieces from the rolled sheets (thickness $1 \mathrm{~mm}$ ).

To reach the equilibrium and defect free state according to Ref. [4], a set of samples was annealed at $580^{\circ} \mathrm{C} / 24 \mathrm{~h}$ and aged at $300^{\circ} \mathrm{C}$ under vacuum for a long time ( $4 \mathrm{~d}$ and $60 \mathrm{~d}$, respectively). To study the changes of the defect structure in more detail, isochronal annealing $(20 \mathrm{~min})$ up to $620^{\circ} \mathrm{C}$ has been performed using another set of samples.

$\mathrm{X}$-ray measurements were used to determine the lattice parameters in the cast, the deformed as well as the aged state. DSC measurements should demonstrate the formation of the superstructures $\mathrm{Cu}_{3} \mathrm{Mn}$ and $\mathrm{Cu}_{5} \mathrm{Mn}$ by pointing out small transformation heats resulting from solid state reactions. In the transition range heat is released and a peak is indicated. Our measurements were carried out with a device from NETZSCH. The heating rate amounts to $2 \mathrm{~K} / \mathrm{min}$.

The positron lifetime measurements were performed at the conventional device at MLU Halle with a time resolution of $278 \mathrm{ps}$ (FWHM). The source supporting foils consisted of $\mathrm{Al}$ with a thickness of $2 \mu \mathrm{m}$. The source correction was calculated to $11.9 \%$ using a formula given in the literature [8]. The source correction terms were estimated to have a lifetime (intensity) of $165 \mathrm{ps}(88 \%)$ and $465 \mathrm{ps}(12 \%)$ and are due to annihilations in the source supporting Al-foil and at the ${ }^{22} \mathrm{NaCl} / \mathrm{Al}$ interface and the activity itself, respectively. All measurements were 
carried out at room temperature $\left(20^{\circ} \mathrm{C}\right)$. The evaluations of the time spectra were performed by an updated version of the well-known POSITRONFIT EXTENDED program package [9].

\section{Results and discussion}

The results of the X-ray measurements show that the treatment did not influence the values of the lattice parameters, but the chemical composition of the studied alloys. The measured lattice parameters are shown in Table.

\section{TABLE}

Lattice parameters of CuMn (radiation $\mathrm{Cu}$ ).

\begin{tabular}{c|c|c}
\hline & $\mathrm{Cu}_{3} \mathrm{Mn}$ & $\mathrm{Cu}_{5} \mathrm{Mn}$ \\
\hline$a=b(\mathrm{~A})$ & 2.61 & 2.60 \\
\hline$c(\mathrm{~A})$ & 3.69 & 3.67
\end{tabular}

The interpretation of the DSC measurements show that the transition from the ordered $\gamma$-range to the CuMn-phase takes place at nearly $450^{\circ} \mathrm{C}$ for $\mathrm{Cu}_{3} \mathrm{Mn}$ and about $400^{\circ} \mathrm{C}$ for $\mathrm{Cu}_{5} \mathrm{Mn}$.
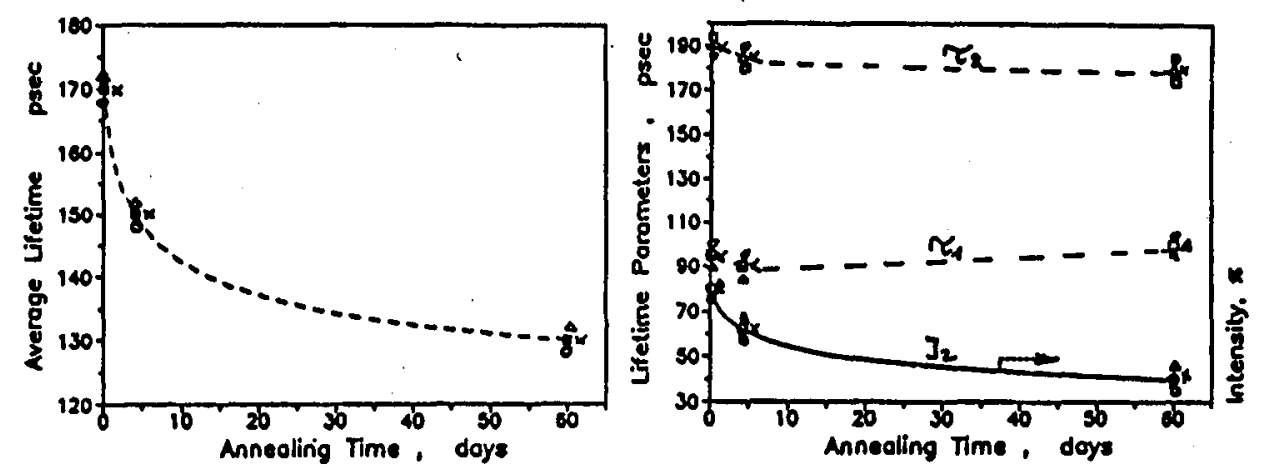

Fig. 2. Average positron lifetime $\bar{\tau}$ and lifetime parameters $\tau_{1}, \tau_{2}$ and $I_{2}$ as a function of annealing time (annealing temperature $300^{\circ} \mathrm{C}$ ), in $\mathrm{Cu}_{3} \mathrm{Mn}-\triangle$ cold rolled, $\circ$ cold hammered, in $\mathrm{Cu}_{5} \mathrm{Mn}-\square$ cold rolled, $x$ cold hammered.

In Fig. 2 the development of the average positron lifetime $\tau$ and the lifetime parameters $\tau_{1}, \tau_{2}$ and $I_{2}$ of all $\mathrm{Cu}-\mathrm{Mn}$ samples are presented as a function of the annealing time at $300^{\circ} \mathrm{C}$.

The possible decomposition of the measured lifetime spectra into two components points out that positrons can either be trapped by lattice defects $\left(\tau_{2}, I_{2}\right)$ or annihilate as free positrons $\left(\tau_{1}, I_{1}\right)$. Using the one-defect trapping model the bulk lifetime can be calculated as

$$
\lambda_{\mathrm{b}}=1 / \tau_{\mathrm{b}}=I_{1} / \tau_{1}+I_{2} / \tau_{2}
$$


Above, $\tau_{2}=\lambda_{2}^{-1}$ represents the trapped positron lifetime in a monovacancy. It is supposed that vacancies and/or dislocations could be trapping centers depending on the annealing time.

It can be seen that the annealing behaviour is equal for both alloys and both deforming processes. In Ref. [4] an annealing temperature of $160^{\circ} \mathrm{C}$ has been assumed to be sufficient for obtaining an ordered and defect free state. However, even after our final annealing $\left(300^{\circ} \mathrm{C} / 60 \mathrm{~d}\right)$ it is obvious (see Fig. 2) from the presence of a long-living component $\tau_{2}$ with an intensity $I_{2}$ of about $40 \%$ that no defect free state of the alloys has been reached. The average positron lifetime $\bar{\tau}$ for all samples in the final state amounts to $130 \mathrm{ps.}$

The lines connecting measuring points in Figs. 2-4 presented in this work have been drawn as a guide for the eyes only. Typical errors are given in Fig. 3 and Fig. 4 for some points only.

To study the changes of the defect structure in more detail, isochronal annealing $(20 \mathrm{~min})$ up to $620^{\circ} \mathrm{C}$ has been performed. The results for the average positron lifetime $\bar{\tau}$ are presented in Fig. 3.
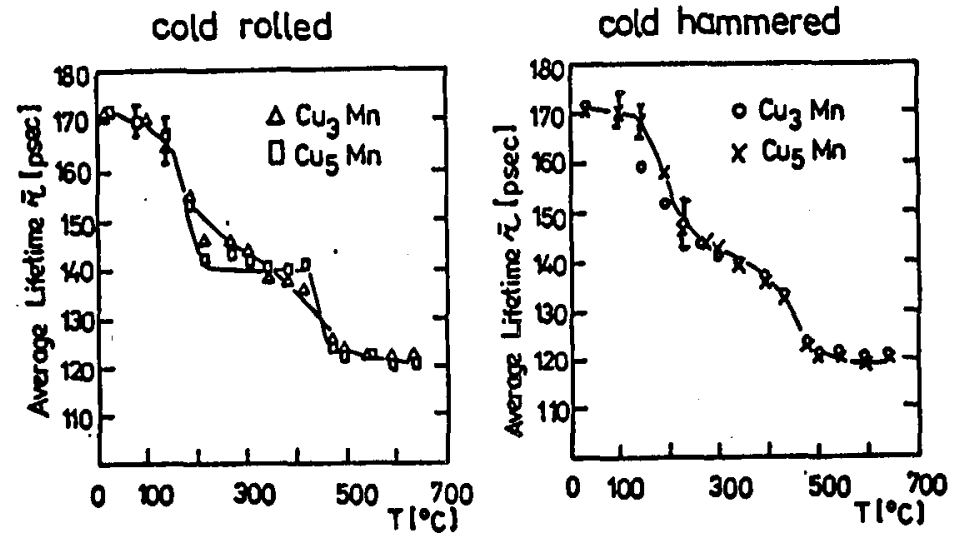

Fig. 3. Average positron lifetime $\bar{\tau}$ as a function of isochronal annealing temperature.

The development of $\bar{\tau}$ due to isochronal annealing exhibits the existence of two annealing steps. The first one at about $150^{\circ} \mathrm{C}$ should be connected with vacancies, whereas the second one might be due to dislocations. For all samples finally $\bar{\tau}$ reached a value of 120 ps. This value is close to the average positron lifetime for $\mathrm{Cu}$ known from the literature $\left(\bar{\tau}_{\mathrm{Cu}}=122 \mathrm{ps}\right.$ [10]). Because the studied compositions $\mathrm{Cu}_{3} \mathrm{Mn}$ and $\mathrm{Cu}_{5} \mathrm{Mn}$ belong to the Cu-rich part of the $\mathrm{Cu}-\mathrm{Mn}$ system this agreement seems to be reasonable. Saturation trapping in vacancies is reported to increase the positron lifetime in $\mathrm{Cu}$ by about $60 \mathrm{ps}$ [10], i.e. our interpretation of the first annealing step (Fig. 3) as being due to vacancies seems to be supported too.

A decomposition of the measured positron lifetime spectra due to isochronal annealing up to $620^{\circ} \mathrm{C}$ is presented in Fig. 4.

Generally, a decrease in the intensity $I_{2}$ from about $80 \%$ at the beginning 


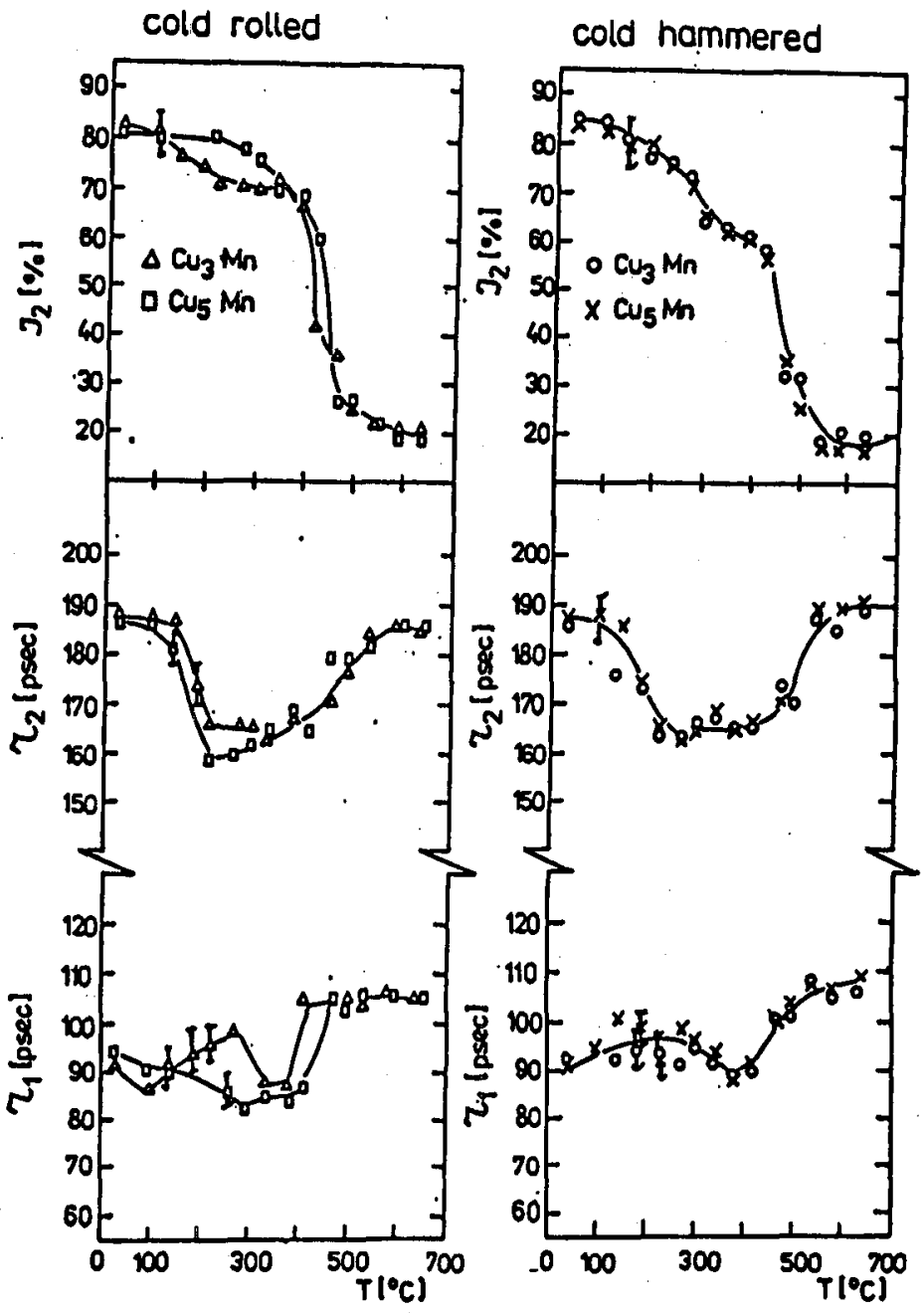

Fig. 4. Positron lifetime parameters $\tau_{1}, \tau_{2}$ and $I_{2}$ as a function of isochronal annealing temperature.

of the annealing procedure to about $20 \%$ in the final state indicates the disappearence of lattice defects, which is not complete even due to the applied heat treatment. The interpretation of the changes in the lifetime component $\tau_{2}$ is not so straightforward. Their decrease to a value of about $160 \mathrm{ps}$ seems to really indicate the annealing of vacancies up to about $200^{\circ} \mathrm{C}$. The again observed increase in $\tau_{2}$ at higher temperatures might be connected with the formation of Mn-precipitations due to the transition from the ordered $\gamma$-CuMn region to the CuMn-phase. However, this guess needs further clarification. It is also planned to use Kossel-technique to enlighten the role of dislocations, which has been assumed from the changes of the mean lifetime $\bar{\tau}$ (Fig. 3). 


\section{Conclusions}

Structural information about the lattice parameters of the alloys has been revealed from X-ray measurements.

The results from positron lifetime measurements do not support the conclusions from the literature that an annealing temperature of $160^{\circ} \mathrm{C}$ is sufficient to obtain the defect free state of these alloys.

Further work is necessary in order to clarify the annealing behaviour and defect characteristics of the above-mentioned alloys.

\section{Acknowledgment}

We are thankful to R. Krause-Rehberg and A. Polity for the possibility to perform positron lifetime measurements at MLU Halle-Wittenberg.

\section{References}

[1] G. Brauer, L. Liszkay, B. Molnar, R. Krause, Nucl. Eng. Des. 127, 47 (1991).

[2] G. Solt, F. Frisius, W.B. Waeber, in: Radiation Embrittlement of Nuclear Reactor Pressure Vessel Steels, An International Review, Ed. L.E. Steele, Vol. 3., ASTM STP 1011, American Society for Testing and Materials, Philadelphia 1989, p. 229.

[3] P.A. Beaven, F. Frisius, R. Kampmann, R. Wagner, J.R. Hawthorne, in: Radiation Embrittlement of Nuclear Reactor Pressure Vessel Steels, An International Review, Ed. L.E. Steele, Vol. 3 ASTM STP 1011, American Society for Testing and Materials, Philadelphia 1989, p. 243.

[4] W. Köster, T. Gödecke, Z. Met.kd. 80, 761 (1989).

[5] T. Gödicke, W. Köster, Z. Met.kd. 80, 766 (1989).

[6] R. Reihshner, W. Pfeiler, J. Phys. Solids 46, 1431 (1985).

[7] Binary Alloy Phase Diagram, Ed. B. Massalski, Vol. 1, American Society for Metals, Metals Park, Ohio 1986, p. 84.

[8] H. Surbeck, Helv. Phys. Acta 50, 705 (1977).

[9] P. Kirkegaard, N.J. Pedersen, M. Eldrup, Tech. Rep. Ris $\varnothing-M-2740$, Ris $\varnothing$ Nat. Lab., Roskilde (Denmark) 1989.

[10] I.K. MacKenzie, in: Positron Solid-State Physics. Proc. Int. School of Physics "Enrico Fermi", Course LXXXIII, Varenna on Lake Como (Italy), 1981, Eds. W. Brandt, A. Dupasquier, North-Holland Publ. Co., Amsterdam 1983, p. 196. 